Research Article

\title{
Mass Culturing of Mycetophagous Nematode Aphelenchus avenae (Nematoda: Aphelenchidae) in vitro System by Feeding on Pathogenic Fungus
}

\section{Salma Javed and Samreen Khan*}

National Nematological Research Centre, University of Karachi, Karachi-75270, Pakistan.

\begin{abstract}
The production phenomenon of fungal feeding nematode Aphelenchus avenae have been thoroughly examined in vitro system by ensuring Potato Dextrose Agar (PDA). Two fungal species Fusarium oxysporum and Aspergillus niger were examined for their aptitude to assist the population rate of the said species. Nematodes were collected from soil around the rhizospheres of sponge gourd (Luffa cylindrical L.) field in the vicinity of National Nematological Research Centre, University of Karachi and further processed by Cobb's sieving and Baermann's funnel techniques. Specimens were killed, fixed and identified up to species level under light microscope. Afterward, hundred fresh handpicked nematodes were inoculated on both fully grown fungal species at $25^{\circ} \mathrm{C}$. The nematode attraction and mass culture were appeared on Fusarium oxysporum only. On the first week, propagation rate was noted approximately $2.5 \times 10^{3}$ followed by $3.9 \times 10^{3}$ on the second week and finely after three weeks incubation period the greatest multiplication rate estimated up to $8.9 \times 10^{3}$; however, the same did not appeared on Aspergillus niger and result was found negative. The main purpose of captioned study was to report mass culturing of parasitic Aphelenchus avenae and their relationship and further explore these nematodes under field circumstances to control many pathogenic soil-borne fungi because this is the first study conducted on the subject experiment in Pakistan.

Received | December 26, 2020; Accepted | April 03, 2021; Published | June 02, 2021

*Correspondence | Samreen Khan, National Nematological Research Centre, University of Karachi, Karachi-75270, Pakistan; Email: samreenkhan3336@gmail.com

Citation | Javed, S. and S. Khan. 2021. Mass culturing of mycetophagous nematode Aphelenchus avenae (Nematoda: Aphelenchidae) in vitro system by feeding on pathogenic fungus. Sarbad Journal of Agriculture, 37(2): 675-682.

DOI | http://dx.doi.org/10.17582/journal.sja/2021/37.2.675.682

Keywords | Aphelenchus avenae, Fusarium oxysporum, Aspergillus niger, Fungivorous, Mass culturing, Pathogenic
\end{abstract}

\section{Introduction}

$\mathrm{T}$ he ecosystems consist of various kinds of microscopic organisms including archaea, bacteria, fungi, protozoa, and nematodes. Collectively, these organisms interact with each other and as well as with plants to achieve ecosystem functions. Their interactions ensue through various type of mechanisms likewise mutualism, parasitism, predation or competition (Topalovic and Heuer, 2019). In the terrestrial ecosystem nematodes and fungi are knowing the abundant organisms and generally co-existing around roots of plants as well as crops with substantial effects upon forestry and agriculture. Therefore, the relationships between them whether antagonistic or mutualistic, direct or indirect, attracted significant attention (Zhang et al., 2020).

The populace of fungivorous nematodes in soil are basically subordinate than plant parasitic or bacterial feeder nematodes (Freckman and Caswell, 1985) but good fungal hosts being there, the population 
densities of these nematodes could rise quickly (Duyck et al., 2009; Quénéhervé, 2008; Poornima et al., 2007; Arancon et al., 2003; Hoffman and S'Jacob, 1989). However, antagonistic relationship existing between nematodes and fungi are frequent as they varied. Some nematodes likewise Aphelenchus avenae, Aphelenchoides spp., as well as Paraphelenchus acontioides may fed upon fungi (Lamondia and Timper, 2016). Among these, $A$. avenae is ubiquitous fungivores nematode and has been confirmed and verified as biological agent to control soil-borne plant pathogens (Haraguchi and Yoshiga, 2020; Azimi, 2018; Lamondia and Timper, 2016; Jun and Kim, 2004). They are high reproduction rate, limited life cycle, highly colonized capacity and are potential to any disturbances (Bonger, 1990; Kibet et al., 2014).

The feeding routine of $A$. avenae is important to recognize their biology and role in ecosystem. A total of $6.1 \mathrm{ng}$ of Nitrogen consumes by $A$. avenae from fungal biomass in 24 hours which rises nitrogen mineralization and release of $\mathrm{CO} 2$ (Ingham et al., 1985), thus promising to soil fertility (Chen and Ferris, 1999). Synergistic and antagonistic interactions between fungi and nematodes have been reported (Ragozzino and D' Errico, 2011). While, fungivorous nematode parasitizing fungi, feed on their cell contents and subsequently decreasing fungal biomass (Wolfarth et al., 2013), they can also co-exist with fungal endophytes in a cultivation-based mutualism, where the nematode established the growth of its favorable fungus (Baynes et al., 2012). However, in case of parasitic interaction between fungivorous nematodes and pathogenic fungi, the disease severity is reduced (Karuri et al., 2014; Ruess and Dighton, 1996).

Feeding behaviour of fungivorus nematode has dissimilar effect on soil ecology. High grazing on mycorrhizal fungi may limit mycorrhizal growth and nutrient uptake by host plants which is complicatedness to plants. This can direct to lessening in the yield of mycorrhizal host plants (Ruess et al., 2000).

Pathogenic Fusarium oxysporum is a source of vascular wilt, stunting, chlorosis, die back and death of plant in numbers of crops. They achieve entrance via roots and assault vascular system from where they get access throughout plant. In East Africa Fusarium wilt has reported and as well as in Kenya wherever it effectively minimized the fiber quality and yields (ICAC, 2003). At field level progress of Fusarium wilt is depending upon susceptibility of the crop, fungal virulence, kind of soil and fecundity, environmental circumstances and associations with some other organisms, i.e., nematodes.

Fungivorous nematodes could be cultured on various fungal species, including pathogenic, saprophytic and mycorrhyzal fungi (Freckman and Caswell, 1985; Giannakis and Sanders, 1989; Ruess and Dighton, 1996; Bae and Knudsen, 2001; Tahir et al., 2017). $A$. avenae feeds over 52 genera of fungi mostly plant pathogens and is an important biological control agent (Mankau and Mankau, 1963; Giannakis and Sanders, 1989; Okada and Ferris, 2001; Okada, 2006; Karuri et al., 2014; Tahir et al., 2017). However, our result also agreed with the statements given by researchers (Okada, 2006; Karuri et al., 2014; Tahir et al., 2017) who said $A$. avenae reproduced on many species of Fusarium. The present objective of this article is to report mass culture of parasitic nematode $A$. avenae and provide their evidence or relationship between them as mentioned in this article, and in future to apply these nematodes under field condition to control various pathogenic soil borne fungi and other plant parasitic nematodes for better agricultural productions and soil fertility. It is basically first systematic study focused on mass culture of fungivorous nematode $A$. avenae under laboratory condition by feeding upon fungus on PDA and is thoroughly described in this article.

\section{Materials and Methods}

\section{Isolation of fungus}

The pure culture of Fusarium oxysporum used in the experiment was obtained from Pakistan Agriculture Research Council (PARC), University of Karachi, Karachi, Pakistan while Aspergillus niger were retrieved in laboratory from infected banana leaves. For this purpose, leaves were thoroughly washed and cut into $3 \mathrm{~mm}$ pieces via sterilized scalpel. Surface sterilized with $70 \%$ ethyl alcohol for few seconds followed by 2-3 times washed with sterilized water and transferred aseptically to fresh solidifying PDA plates (Figure 1A and B), supplemented with streptomycin $(100 \mathrm{mg} / \mathrm{I})$ and incubated at $25^{\circ} \mathrm{C}$ for 3-5 days (Aneja, 2003). They were further sub-cultured aseptically on other fresh solidifying PDA plates or slants for maintaining their pure biomass for further work. 
Extraction of nematodes

Nematodes were isolated from soil of sponge gourd (Luffa cylindrical L.) from field of National Nematological Research Centre, University of Karachi, Karachi, Pakistan. This soil sample was processed by Cobb's sieving and decanting technique (Cobb, 1918). Retrieved nematodes were further purified through modified Baermann's funnel technique (Baermann, 1917).

\section{Mounting of nematodes for confirmation of Aphelenchus species}

Fresh and alive Aphelenchus were handpicked under stereomicroscope. These Aphelenchus were heat killed and conserved in TAF (Tri-ethanol-amine Formaldehyde) including $8 \%$ formalin and 2\% Triethanol-amine in distilled water (Courtney et al., 1955). Permanent mounting was done in a small drop of pure glycerin, protected with $19 \mathrm{~mm}$ of cover slip and fixed firmly by paraffin wax (Siddiqui, 2000). Measurements were taken by utilizing de Man's formula (1884) with the assistance of an ocular micrometer in a compound microscope up to species level. Photographs were captured via Nikon DS-fi-1 camera fixed with Nikon Eclipse- E-400 compound microscope.

\section{Media preparation}

The source of medium used in the experiment was Potato Dextrose Agar (PDA). Peeled potatoes about $200 \mathrm{gm}$ were boiled in $1000 \mathrm{ml}$ distilled water for 45 minutes. Sugar (20gm) and Agar (16gm) were added and autoclaved at 15 psi for 1 hour. Distributed into sterilized petri dishes and test tubes aseptically under laminar air flow.

\section{Inoculation of $A$. avenae}

About 100 nematodes (including 90 females and 10 males) for each culture were added by pipette in petri dishes aseptically to fully grown pure fungal cultures of Fusarium oxysporum and Aspergillus niger (Figure $1 \mathrm{C}$ and D). Subsequently, petri dishes were sealed by parafilm (PM-996) and incubated at $25^{\circ} \mathrm{C}$.

\section{Retrieved of nematodes from culture media}

After three weeks incubation period, distilled water was added in culture plate, gently shaken and nematodes were collected in large glass petri plate. Average propagation rate was calculated and repeated three times in an open counting chamber in $1 \mathrm{ml}$ suspension under binocular microscope.
Data analysis

Collected data were analyzed correlation with respect of growth and time period by using Statistical Analysis System (SAS) program.

\section{Results and Discussion}

Identification of nematode species

Aphelenchus avenae Bastian, 1865

Measurements: (Table 1)

Table 1: Morphometric data of $A$. avenae Bastian, 1865. All measurements are in $\mu m$ in the form of Mean $\pm S D$ (range).

\begin{tabular}{lll} 
Characters & Female $(\mathbf{n}=\mathbf{1 0})$ & Male $(\mathbf{n = 5})$ \\
\hline L & $720 \pm 45.1(666-749)$ & $650 \pm 62.0(600-743)$ \\
a & $26.6 \pm 1.66(22.8-28.9)$ & $27.1 \pm 1.616(25.1-28.9)$ \\
b' & $4.22 \pm 0.52(3.4-4.9)$ & $3.8 \pm 0.47(3.4-4)$ \\
c & $27.3 \pm 3.00(24-33.6)$ & $25.0 \pm 2.09(22.7-27)$ \\
c' & $1.53 \pm 0.14(1.3-1.8)$ & $1.36 \pm 0.12(1.2-1.4)$ \\
V\% & $74.5 \pm 2.17(69-76.7)$ & - \\
Stylet & $15.5 \pm 0.67(14-16)$ & $15.2 \pm 0.4(15-16)$ \\
Spicule & - & $26 \pm 1.67(24-28)$ \\
Gubernacu- & - & $14.8 \pm 0.97(14-16)$ \\
lum & &
\end{tabular}

Brief description: Body usually long, cylindershaped, ventrally arcuate or straight to some extent. Lateral field with 10-12 incisures. Lip region low, round to flattened, non-offset. Stylet long without basal swelling. Procorpus cylindrical. Median bulb well developed, oval-shaped and conspicuous valve plates located centrally. Dorsal esophageal gland orifice opening into lumen of median bulb. Esophago-intestinal junction located posteriorly to the base of median bulb and measured 70-100 $\mu \mathrm{m}$ from head region. Dorsal oesophageal gland usually well developed, overlapped the intestine on the left subdorsal side. Nerve ring located posterior to metacorpus and excretory pore located posteriorly to nerve ring.

Reproductive system mono-prodelphic. Post uterine sac present and well developed. Vulva protuberant. Female tail broad, cylindrical and bluntly rounded. Male tail short, conoid, narrowing posteriorly to a pointed end. Spicules slender, paired, ventrally arched, cephalated proximally. Gubernaculum linear. Bursa well developed. Four pairs of bursal papillae present. 


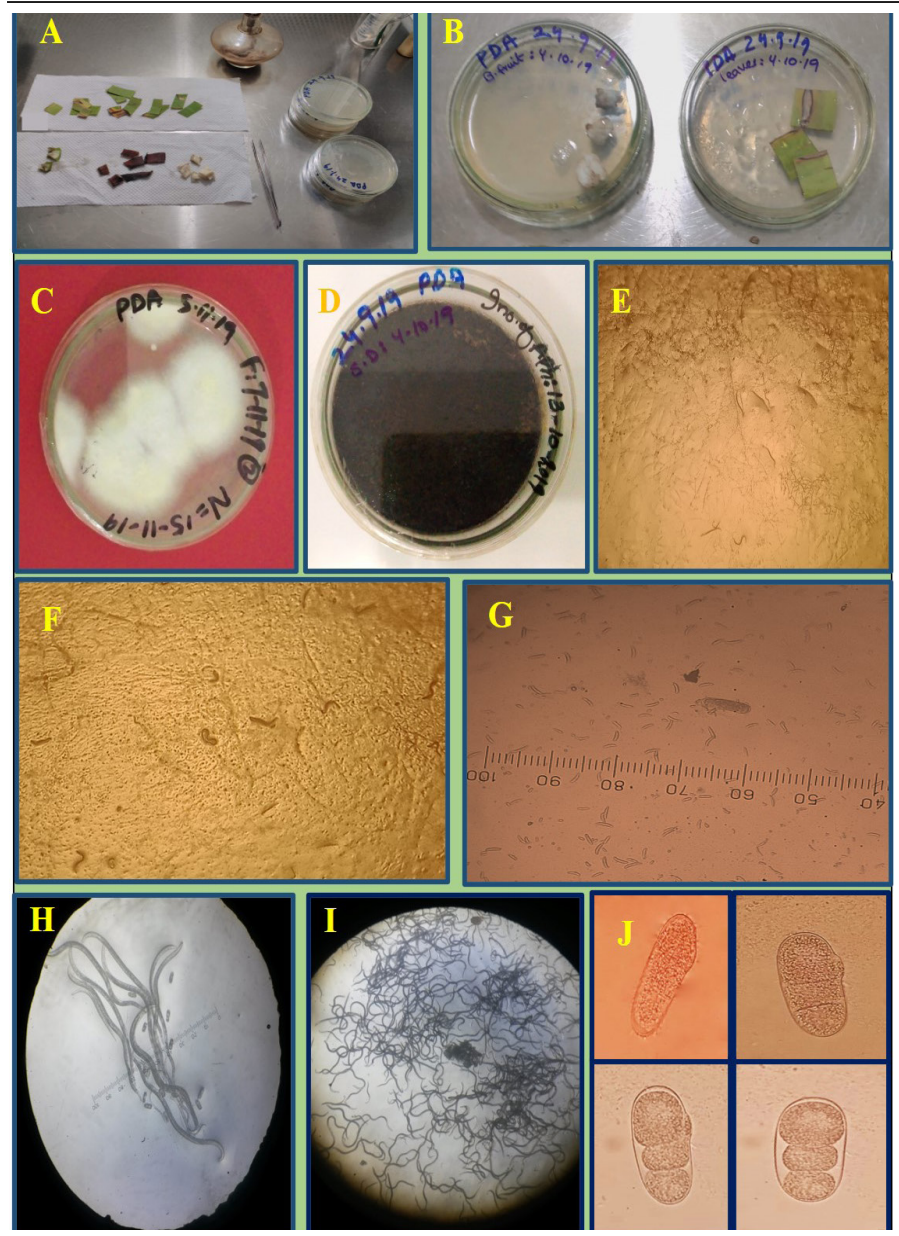

Figure 1: $A$ and B. Isolation of Aspergillus niger from banana leaves; C. Pure culture of Fusarium oxysporum; D. Pure culture of Aspergillus niger; $E$ and $F$. Interaction between fungus and nematodes; G. Fungal spores; H. Bunch of nematodes along with eggs; I. Mass culture of A. avenae after grew on F. oxysporum; J. Various embryogenetic stages of $A$. avenae.

Eggs: Eggs of $A$. avenae were found in different embryological stages and morphologically same like other nematode species Figure 1J. Temporary slides and measurements were made for morphological studies. The eggs were crystal clear, elongate in shape and about $80-87.5 \mu \mathrm{m}$ long and 36-37.5 $\mu \mathrm{m}$ wide.

\section{Survival rate and observations highlighted during incubation period}

Two fungal species $F$. oxysporum and Aspergillus niger were examined for (1) F. oxysporum as a good fungal host for nematode, easily mass cultured and pathogenic to plant (2) Aspergillus niger as non-fungal host, easily mass cultured and for comparatively result. Fungal feeder nematode $A$. avenae was used for their aptitude to assist the population rate by ensuring PDA medium. After three weeks incubation period, nematode mass culture was appeared on $F$. oxysporum only. On the first week, propagation rate was noted approximately $2.5 \times 10^{3}$ followed by $3.9 \times 10^{3}$ on the second week and finely after three weeks incubation period the greatest

multiplication rate was estimated upto $8.9 \times 10^{3}$ (Table 2 and Figure 2), while did not observed the attraction of nematode towards the fungus Aspergillus niger and resultantly no multiplications were reported after inoculation of initial calculated nematodes (i.e., 100) for each fungus (Figure 3). It has been confirmed the presence of preferable and non-preferable fungal host. Furthermore, it also observed that nematode preferred mycelia rather than conidia. During the course of incubation process, $A$. avenae was observed in close interaction with fungus through contact of their head with the wall of fungal hyphae (Figure 1E and $G$ ). This close interaction was exhausted after breaking of fungal hyphae and consuming of entire cell contents by the nematodes. Forming of sunken areas in the colonies was observed because of the damaging by fungivorous nematodes. After one week, a bunch of Aphelenchus along with eggs in various embryogenetic stages were surfaced Figure $1 \mathrm{H}$. The numbers of $A$. avenae have been increased many folds and observed that no space existed among them Figure 1I. Moreover, many gravid females in final stage for eviction of eggs from the uterus were also found.

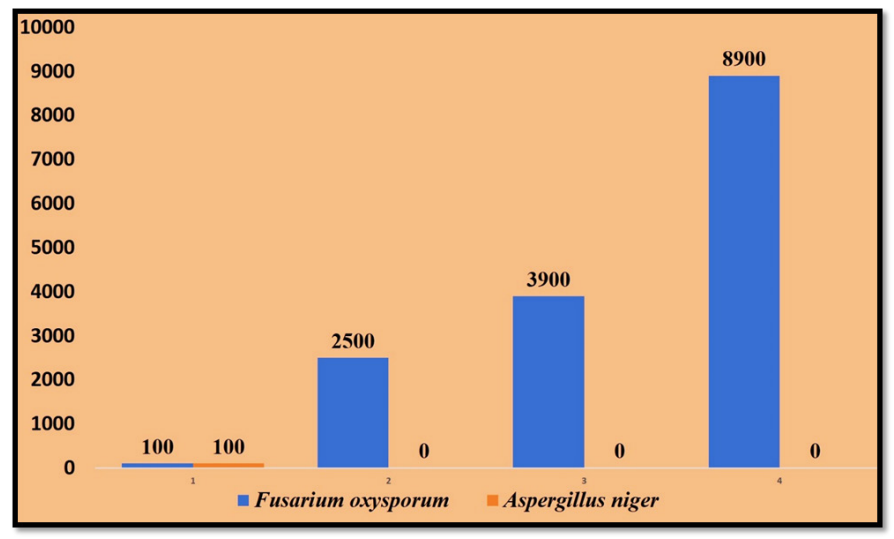

Figure 2: Increasing in population of $A$. avenae on F. oxysporum with no growth on Aspergillus niger during three weeks incubation period.

Table 2: Reproduction rates of $A$. avenae on Fusarium oxysporum and Aspergillus niger.

$\begin{array}{lllll}\text { Species } & \mathbf{1}^{\text {st }} \text { Day } & \mathbf{1}^{\text {st }} \text { Week } & \mathbf{2}^{\text {nd }} \text { Week } & 3^{\text {rd }} \text { Week } \\ \text { Fusarium oxysporum } & 100 & 2500 & 3900 & 8900 \\ \text { Aspergillus niger } & 100 & 0 & 0 & 0\end{array}$

The nematodes were also inoculated in a test tube having pure culture of Fusarium oxysporum Figure 4A. Nematodes moving tracks were noted on surface of PDA. After few days, gradually the changing was observed in general appearance and lessening in fungal mass (Figure 4B and C). Consequently, the PDA June 2021 | Volume 37 | Issue 2 | Page 678 
medium reduced and accordingly moved upward from its primary position inside the tube which indicated that Aphelenchus reproduced themselves by consuming fungus as well as medium (Figure 4D and E). After conducted observations, nematodes were retrieved from culture media and inoculated in a pot having sterilized soil for other experimental purpose in future Figure 5.

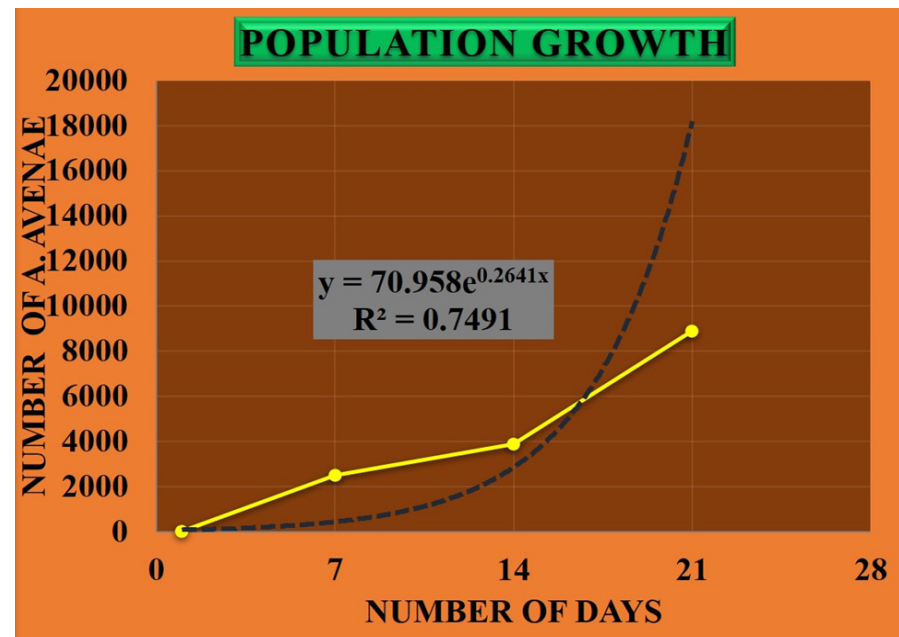

- -Number of Species ---Expon. (Number of Species)

Figure 3: Exponential growth of $A$. avenae on F. oxysporum grew on PDA after three weeks incubation period.

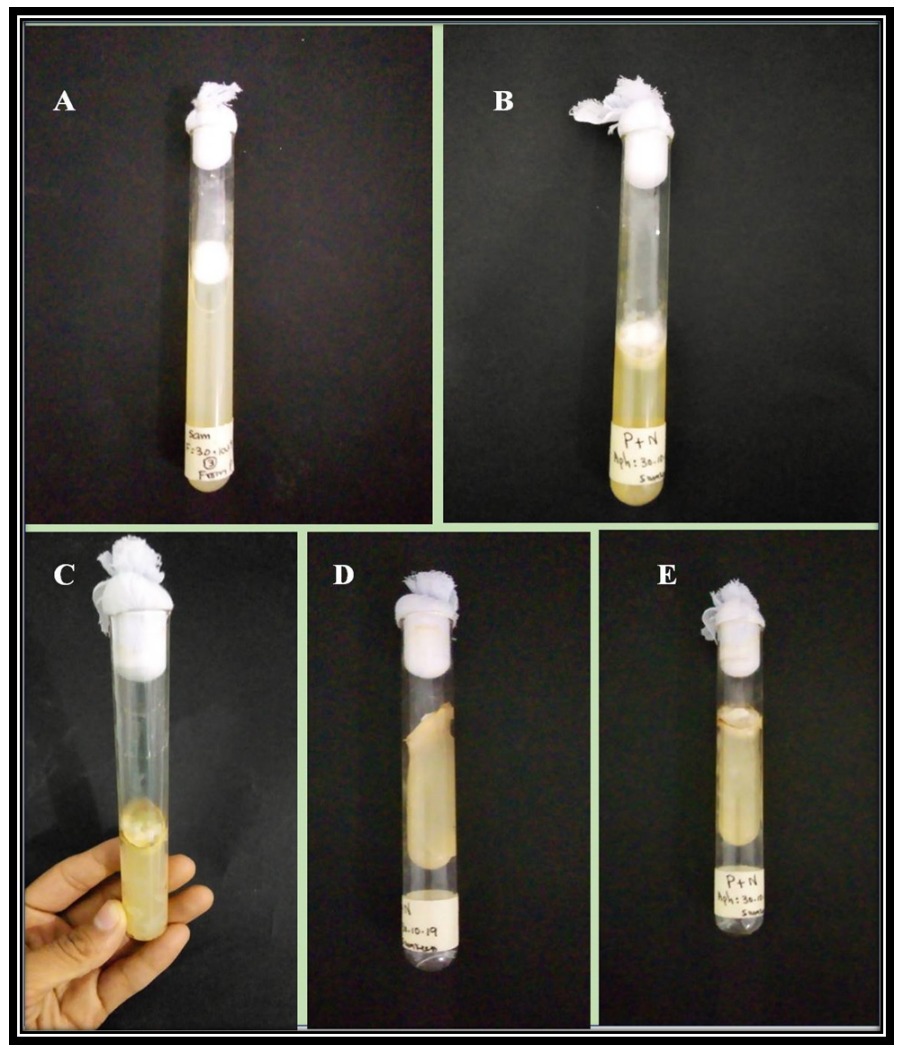

Figure 4: A. Pure culture of F. oxysporum in test tube; $B-C$. Change in appearance and lessening of $F$. oxysporum after inoculation of $A$. avenae; $D-E$. Consuming fungus as well $P D A$ medium by $A$. avenae.

June 2021 | Volume 37 | Issue 2 | Page 679

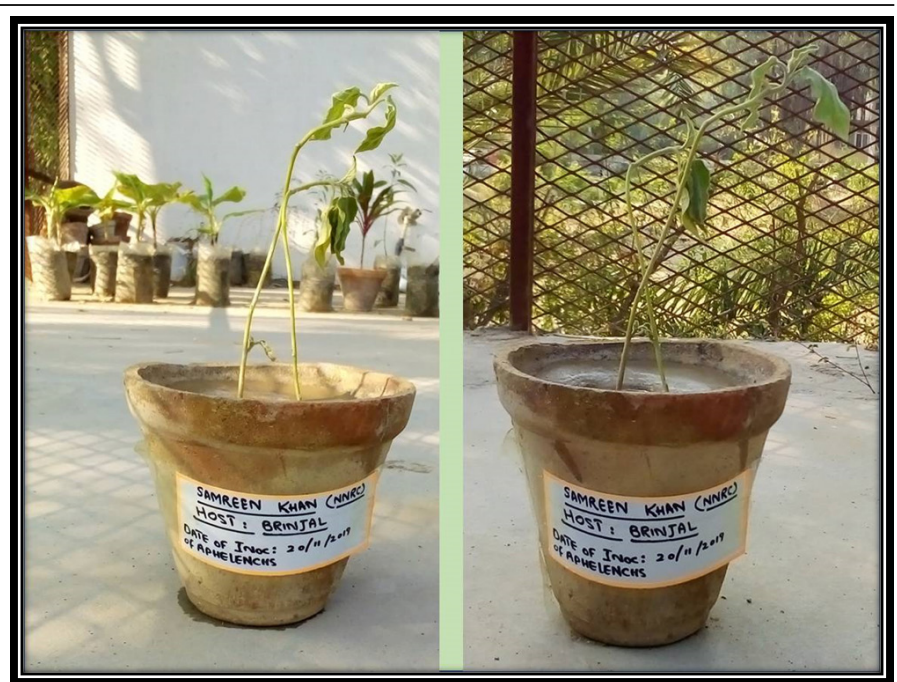

Figure 5: Culturing of $A$. avenae in a pot using brinjal plant.

The fungal feeder nematode $A$. avenae has great capability to produce itself upon feeding several types of fungi in cultivated and also non-cultivated soil, consequently making it distribute globally (Ishibashi et al., 2005). In the present study $A$. avenae was used as a model predator due to their ubiquitous presence in soils of temperate regions where they cohabit with most of the fungal species and easy reproduced themselves in short time. The current research work represented that propagation of the nematode was substantially dissimilar as a result of different fungal species. In current study Fusarium oxysporum was observed the favourable fungal host for support of large multiplication of fungal feeding nematode, A. avenae, in short period as compared Aspergillus niger. Their mouth is intended with the needle like structure (stylet) and well-developed esophageal part (metacorpus) that facilitate them to penetrate the fungal hyphal cell and consumed entire cell contents. Earlier, Rhoades and Linford, 1959, conducted the first systematic research and observed that the $A$. avenae has ensured for Pythium root rot controlling in maize (Zea mays L.) in greenhouse situations. After that, $A$. avenae and some fungivorous species in the genera Aphelenchoides has been experienced in laboratory, greenhouse and in field examination to control variety of phytopathogenic fungi in crops (Friberg et al., 2005).

Many fungivorous nematodes could be reared on media having suitable fungus and established strict damages to fungal cultures. In vitro, the higher multiplication and number of $A$. avenae on Fusarium graminearum (114233) followed by Fusarium oxysporum (47013) and Verticillun dabliae (1500) after 
two weeks incubation period by ensuring solid PDA and Malt extract liquid medium was conducted by Tahir et al., 2017. He observed lower reproduction of $A$ avenae and found dead on liquid culture, support their finding with the statement given by (Grewal et al., 2005) that $A$. avenae could not propagate and surviving in liquid media. Ishibashi et al. (2005) studied that $A$. avenae during feeding in fungal culture, they secrete hydrolytic enzyme which destroyed and hydrolyzed the mycelium of fungus.

In thelightofabove, fewothercases ofinterrelationships and true parasitism between nematodes and fungi is to be worth mentioning. Ishibashi et al. (2000) observed reproductive range of $A$. avenae in semisolid substrate. In another research, $A$. avenae and Aphelenchoides species has been experienced to suppress fungal disease of plants and nitrogen mineralization in soil (Okada, 2006). Damping off of radish due to Pythium spp was also expressed to be controlled through $A$. avenae. Karuri et al. (2014) assess the interrelation between Fusarium oxysporum f. sp. vasinfectum and $A$. avenae on Bt cotton and its isogenic counterpart in greenhouse situaions. Lagerlof et al. (2011) tested the hypothesis through greenhouse experiments about the Aphelenchoides spp. and $A$. avenae that could suppress damping-off due to Rhizoctonia solani in cauliflower seedlings and improve the disease-suppressive impact of compost. In recent study, Haraguchi and Yoshiga (2020) studied that $A$. avenae may contribute to suppress plant parasitic nematode Ditylenchus destructor through fungal control in vitro experiments.

The aforesaid experience proved the veracity of fact with respect to interrelation between $A$. avenae and Fusarium species (Mankau and Mankau, 1963; Okada, 2006; Karuri et al., 2014; Tahir et al., 2017). Although the biocontrol potential of $A$. avenae is well recognized, they have not yet been widely used in applied agriculture or horticulture in the formulation of nematode applications in Pakistan even though they are quite easy to proliferate in huge numbers within short time period. In this point of view, their use perhaps economically realistic as well as environmentally welcoming and should be distributed to growers for field applications.

\section{Conclusions and Recommendations}

The veracity of Nematodes-Fungus relationships has been successfully established in vitro system June 2021 | Volume 37 | Issue 2 | Page 680 for the first time in Pakistan. The said experiment providing evidence that the fungivorous nematodes should be proficient biocontrol agent against various phytopathogenic fungi and other plant parasitic nematodes. It is considered that more investigations from various aspects are needed to be determined the biology of fungivorous nematodes and their substantial influences on soil ecology as well as crop production especially in Pakistan.

\section{Novelty Statement}

The said research article describes rearing of fungal feeding nematodes on their attractive feeds for agricultural importance for the first time conducted in Pakistan. This research work is significant and meaningful because new valuable information obtained from the said experiment and the same will be assisted/ helpful in future for further culturing of plant-parasitic nematodes. Moreover, the said article being a guideline for researchers in the field of plant nematology.

\section{Author's Contribution}

Salma Javed: Supervised the research and critically reviewed the manuscript.

Samreen Khan: Performed the experiment, made photography, analyzed data and drafted the manuscript.

\section{Conflict of interest}

The authors declare no conflict of interest.

\section{References}

Aneja, K.R., 2003. Experiments in microbiology and plant pathology. New Age International Pvt. Ltd., New Delhi.

Arancon, N.Q., P. Galvis, C. Edwards and E. Yardim. 2003. The trophic diversity of nematode communities in soils treated with vermicompost. Pedobiology, 47: 736-740. https://doi.org/10.1078/0031-4056-00752

Azimi, S., 2018. Morphological and molecular characterization of two populations of Aphelenchus avenae (Nematoda: Aphelenchidae) from Iran and their phylogenetic relationships. Biologia.,73:683-691.https://doi.org/10.2478/ s11756-018-0079-5

Bae, Y.S. and G.R. Knudsen. 2001. Influence of 
a fungus-feeding nematode on growth and biocontrol efficacy of Trichoderma harzianum. Phytopathology, 91: 301-306. https://doi. org/10.1094/PHYTO.2001.91.3.301

Baermann, G., 1917. Eineeinfache Methodezur Auffindung von Ankylostomum (Nematoden) Larven in Erdproben Geneesk. Tijdschr. Ned. Lnd., 57: 131-137.

Bastian, H.C., 1865. Monograph on the Anguillulidae, or free nematoids, marine, land, and freshwater; with descriptions of 100 new species. Trans. Linn. Soc. Lon., 25: 73-184. https://doi.org/10.1111/j.1096-3642.1865. tb00179.x

Baynes, M.A., D. Russell, G. Newcombe, L. Carta, A. Rossman and A. Ismaiel. 2012. A mutualistic interaction between a fungivorous nematode and a fungus within the endophytic community of Bromus tectorum. Fungal Ecol., 5: 610-623. https://doi.org/10.1016/j.funeco.2012.03.004

Bonger, T., 1990. The maturity index: an ecological measure of environmental disturbance based on nematode species composition. Oecologia, 83: 14-19. https://doi.org/10.1007/BF00324627

Chen, J. and H. Ferris. 1999. The effects of nematode grazing on nitrogen mineralization during fungal decomposition of organic matter. Soil Biol. Biochem., 31: 1265-1279. https:// doi.org/10.1016/S0038-0717(99)00042-5

Cobb, N.A., 1918. Estimating the nema population of soil. Agric. Tech. Circ. US Dept. Agric., I., pp. 48.

Courtney, W.D., D. Polley and V.L. Miller. 1955. TAF, an improved fixative in nematode technique. Plant Dis. Rep., 39: 570-571.

De Man, G., 1884. Diefrei in der reinen Erde und in sussen Wasser lebenden Nemaloden der niederldndischen Fauna-Eine systemalischefaunislische Monographie, Leiden, The Nemerlands, pp. 206. https://doi.org/10.5962/ bhl.title.46884

Duyck, P.F., S. Pavoine and P. Tixier. 2009. Host range as an axis of niche partitioning in the plant-feeding nematode community of banana agroecosystems. Soil Biol. Biochem., 41: 1139-1145. https://doi.org/10.1016/j. soilbio.2009.02.020

Freckman, N.W. and E.P. Caswell. 1985. The ecology of nematodes in agroecosystems. Ann. Rev. Phytopathol., 23: 275-296. https://doi. org/10.1146/annurev.py.23.090185.001423
Friberg, H., F. J. Lagerlo and B. Ramert. 2005. Influence of soil fauna and fungal plant pathogens in agricultural and horticultural systems. Bio-cont. Sci. Technol., 15: 641-658. https://doi.org/10.1080/09583150500086979

Giannakis, N. and F.E. Sanders. 1989. Interactions between mycophagous nematodes, mycorrhizal and other soil fungi. Agric. Ecosyst. Environ., 29: 163-167. https://doi.org/10.1016/01678809(90)90270-N

Grewal, P.S., R.U. Ehlers and D.I. Shapirollan. 2005. Nematodes as biocontrol agents. Wallingford, UK: CABI Publishing. pp. 505. https://doi.org/10.1079/9780851990170.0000

Haraguchi, S. and T. Yoshiga. 2020. Potential of the fungal feeding nematode Aphelenchus avenae to control fungi and the plant parasitic nematode Ditylenchus destructor associated with garlic. Biol. Control., 143: 1-7. https:// doi.org/10.1016/j.biocontrol.2020.104203

Hoffman, T.W. and J.J. S'Jacob. 1989. Distribution and dynamics of mycophagous and microvorous nematodes in potato fields and their relationship to some food sources. Ann. Appl. Biol., 115: 291-298. https://doi. org/10.1111/j.1744-7348.1989.tb03387.x

ICAC, 2003. Assessment of the impact and main dynamics of cotton diseases affecting in particular small-scale production systems in Southern and Eastern Africa. http://www. icac.org/projects/CommonFund/seacf_disease/ proj_11_final.pdf. Accessed $25^{\text {th }}$ December, 2013.

Ingham, R.E., J.A. Trofymow, E.R. Ingham and D.C. Coleman. 1985. Interactions of bacteria, fungi, and their nematodes grazers, effects on nutrient cycling and plant growth. Ecol. Monogr., 55: 119-140. https://doi. org/10.2307/1942528

Ishibashi, N., M.D. Ali and M. Saramoto. 2000. Mass production of fungivorous nematode, Aphelenchus avenae Bastain, 1865, on industrial vegetable/animal waste. Jap. J. Nematol., 30: 8-17. https://doi.org/10.3725/jjn1993.30.12_8

Ishibashi, N., S. Takayama and E. Kondo. 2005. Propagation and feeding behaviour of the mycetophagous nematode, Aphelenchus avenae, on four species of soil fungi. Nemato. Res., Japanese J. Nematol., 35: 13-19. https://doi. org/10.3725/jjn1993.35.1_13 
Jun, O.K. and Y.H. Kim. 2004. Aphelenchus avenae and antagonistic fungi as biological control agents of Pythium spp. J. Plant Pathol., 20: 271-276. https://doi.org/10.5423/ PPJ.2004.20.4.271

Karuri, H.W., R. Amata., N. Amugune and C. Waturu. 2014. Interaction of Fusarium oxysporum f. Sp. Vasinfectum and the fungal feeding nematode Aphelenchus avenae on $\mathrm{Bt}$ cotton. J. P1. Pathol., 96(1): 183-188.

Kibet, T.K, J. Kinyua, D. Kariuki, E.G. Mamati, J. Onguso and E. Wafula. 2014. Occurrence of Fungivorous Nematodes in Ngere Tea Catchment Area, Murang'a County, Kenya. Int. J. Life Sci. Res., 2: 89-96.

Lagerlof, Y., C. Insunza, B. Lundegardh and B. Ramert. 2011. Interaction between a fungal plant disease, fungivorous nematodes and compost suppressiveness. Soil. Plant Sci., 61: 372-377. https://doi.org/10.1080/09064710.2 010.488655

Lamondia, J. and P. Timper. 2016. Interactions of microfungi and Plant-parasitic nematodes. In: Biology of Microfungi. Springer International Publishing: Berlin/ Heidelberg, Germany.

Mankau, R. and S.K. Mankau. 1963. The role of mycophagous nematodes in the soil. The relationships of Aphelenchus avenae to phytopathogenic soil fungi. In: J. Doeksen and J. van der Drift, eds. Soil organisms, The Netherlands: North-Holland Publishing Co. pp 271-280.

Okada,H.,2006. Ecology of fungivorous nematodes and their use for suppression of plant diseases. Bull. Nat. Agric. Res. Cen. for Tohoku., 105: 155-197.

Okada, H. and H. Ferris. 2001. Temperature effects on growth and nitrogen mineralization of fungi and fungal-feeding nematodes. Plant Soil., 234: 253-262. https://doi. org/10.1023/A:1017957929476

Poornima, K., K. Angappan, R. Kannan, N. Kumar, M. Kavino, and T. N. Balamohan. 2007. Interactions of nematode with the fungal Panama wilt disease of banana and its management. Nematol. Medit., 35: 35-39.
Quénéhervé, P., 2008. Integrated management of banana nematodes. In: Ciancio, A. and Mukerji, K.G. (Eds.), Integrated management of fruit crops nematodes. Springer, The Netherlands, pp. 1-54. https://doi.org/10.1007/978-1-40209858-1_1

Ragozzino, A. and G. D'Errico. 2011. Interactions between nematodes and fungi. A concise review. Redia., 44: 123-125.

Rhodes, H.L. and M.B. Linford. 1959. Control of Pythium root rot by the nematode Aphelenchus avenae. Plant Dis. Rep., 43: 323-328.

Ruess, L. and J. Dighton. 1996. Cultural studies on soil nematodes and their fungal hosts. Nematology, 42: 330-346. https://doi. org/10.1163/004425996X00065

Ruess, L.,J.E.G. Zapata and J. Dighton. 2000. Food preference of a fungal-feeding Aphelenchoides species. Nematology, 2: 223-230. https://doi. org/10.1163/156854100508962

Siddiqi, M.R., 2000. Tylenchida parasites of plant and insects. $2^{\text {nd }}$ Edition. CABI publishing, Wallingford, UK, pp. 833. https://doi. org/10.1079/9780851992020.0000

Tahir,I.E., S.N.Ami, R.A.Haleem and B.S.Shareef. 2017. First record of mycetophagous nematode Aphelenchus avenae in Iraq with description and testing their propagation on different fungus culture. Bull. Iraq Nat. Hist. Mus., 14(3): 251-259. https://doi.org/10.26842/ binhm.7.2017.14.3.0251

Topalovic, O. and H. Heuer. 2019. Plant-nematode interactions assisted by microbes in the rhizosphere. Curr. Issues Mol. Biol., 30: 75-88. https://doi.org/10.21775/cimb.030.075

Wolfarth, F., S. Schrader, E. Oldenburg and J. Weinert. 2013. Nematode-Collembolan interaction promotes the degradation of Fusarium biomass and deoxynivalenol according to soil texture. Soil Bio. Biochem., 57: 903-910. https://doi.org/10.1016/j.soilbio.2012.11.001

Zhang, Y., S. Li, H. Li, R. Wang, K.Q. Zhang and J. Xu. 2020. Fungi nematode interactions: Diversity, ecology, and biocontrol prospects in agriculture. J. Fungi., 6: 1-24. https://doi. org/10.3390/jof6040206 